\title{
How do we handle self-plagiarism in submitted manuscripts?
}

\author{
Vesna Šupak-Smolčic ${ }^{* 1}$, Lidija Bilić-Zulle1,2 \\ ${ }^{1}$ Clinical Institute of Laboratory Diagnostics, Rijeka Clinical Hospital Center, Rijeka, Croatia \\ 2Department of Medical Informatics, Rijeka University School of Medicine, Rijeka, Croatia \\ *Corresponding author: vesnasupak@gmail.com
}

\begin{abstract}
Self-plagiarism is a controversial issue in scientific writing and presentation of research data. Unlike plagiarism, self-plagiarism is difficult to interpret as intellectual theft under the justification that one cannot steal from oneself. However, academics are concerned, as self-plagiarized papers mislead readers, do not contribute to science, and bring undeserved credit to authors. As such, it should be considered a form of scientific misconduct. In this paper, we explain different forms of self-plagiarism in scientific writing and then present good editorial policy toward questionable material. The importance of dealing with self-plagiarism is emphasized by the recently published proposal of Text Recycling Guidelines by the Committee on Publication Ethics (COPE).
\end{abstract}

Key words: editorial policy; research integrity guidelines; self-plagiarism; text-recycling

\section{Introduction}

In terms of research integrity, journal editors very often find themselves in the gray zone of publication ethics. In fact, black-and-white situations are rare in responsible decision making. Self-plagiarism is one of those kinds of issues that can vary from being a clear algorithm-based situation to a complex and undefined case. If plagiarism means stealing other people's ideas or words and presenting them as one's own, does self-plagiarism mean stealing one's own words? If the words were a researcher's in the first place, how can the use of one's own prior published words be defined as intellectual theft? Generally, self-plagiarism is a form of plagiarism, and it should be treated as one. However, the absurd notion of stealing from oneself can provoke such a peculiar feeling that it should be treated differently. Self-plagiarized publications do not contribute scientific value, they merely increase the number of papers published without justification in scientific research and gain undeserved benefit to authors in the form of artifi- cially increased number of published papers. For perspective, the Committee on Publication Ethics (COPE) recently proposed new guidelines for dealing with the delicate issue of self-plagiarism (1).

\section{Forms of self-plagiarism}

To clarify the ethical complexities of self-plagiarism and explain the ways to avoid it, scientists have been trying to define self-plagiarism and to describe its possible forms $(2,3)$. Miguel Roig published a paper in Biochemia Medica with an emphasis on self-plagiarism; he distinguished four types of self-plagiarism: duplicate (redundant) publication, augmented publication, segmented publication, and text recycling (2). However, cases of suspected self-plagiarism do not always fall into one specific group, and unfortunately, universal rules have not been established for each group. The given systematization of self-plagiarism forms is only for the academic purpose of easier interpre- 
tation. Moreover, in some sources text-recycling and self-plagiarism are considered synonyms (1). Editors treat each case individually, but proposed guidelines, such as those in COPE flowcharts, offer great help. This paper intends to describe possible journal policies for each of those four potential groups, anchored on the new COPE guidelines.

\section{Duplicate publication}

Duplicate or redundant publication occurs when an author submits identical or almost identical manuscripts to two different journals. During the submission process, most journals request that authors clearly state whether they have already published this or a similar manuscript or whether this manuscript is currently being considered for publication in another journal. If further analysis reveals a major overlap with an author's former work, then such a submitted manuscript can be considered a duplicate publication (same data, results, discussion). Editors can deal with such a case following the COPE flowchart for handling a submitted manuscript suspected of being a duplicate (redundant) publication (4). COPE flowcharts can be accessed from the official COPE web page (http://www.publicationethics.org) and are available to both editors and authors.

\section{Augmented publication}

Augmented publication occurs when authors add additional data to already published data and submit the new manuscript with new, recalculated results, often with a different title and adjusted study aims. This kind of self-plagiarism is difficult to detect because it is usually not a case of verbatim word plagiarism, which can be easily detected by plagiarism detection software. In most cases of augmented manuscripts, the major overlap is seen within the methods section. As such, editors and readers can be misled to consider it as technical (self) plagiarism, which is usually not sanctioned with the same strictness as plagiarism of other parts of the paper. Nevertheless, if a submitted manuscript shows substantial overlap in the methods section with the author's previous work, then the editor can consider this manuscript for publication only under the following circumstances:
- the author refers to his previous work,

- methods cannot be written in any other form without altering comprehensibility,

- the author clearly states that the new manuscript contains data from a previous publication.

\section{Segmented publication}

Segmented or "salami-sliced" publication refers to the case where two or more papers are derived from the same experiment. Similar to augmented publications, salami-sliced publications are also difficult to detect, and revelation of such act, absent text similarity, is possible only on the hint of reviewers or editors. From the research integrity point of view, this kind of publication generally misleads readers as it prevents them from appreciating the big picture of the overall study, which might be completely different from that seen in the presented segment. Final decision on manuscript acceptance is again on the editor's shoulders but must also be anchored on the condition of inevitable revision, e.g., the author must be asked to refer to his previous publication and explain reasonably the connection of the segmented paper to his previously published work.

\section{Text recycling}

Text recycling is exactly what it says: using large portions of one's own already published text in a new manuscript. This kind of self-plagiarism is easily detected by plagiarism detection software. Despite all alleged reasons that perpetrators of such misconduct give to justify their actions, in most cases it is simply "intellectual laziness", as proposed by Roig (2). For journal editors, this kind of situation can be handled following COPE guidelines (4).

\section{Copyright terms}

An additional issue important for dealing with cases of self-plagiarism is the authors' conscious violation of copyright terms. In most cases, authors sign statements of copyright transfer to journal publishers. Thus, aside from being ethically questionable, self-plagiarism involves a legal issue. To simplify, an author's words, once published, do not 
belong to him anymore. However, cases of legal prosecution of self-plagiarists have been few (3).

\section{Editor's decision}

Ultimately, the editor decides how much similarity between a submitted manuscript and a prior one is too much. Apart from the similarity percentage, the citation of the original article could be helpful for decision making. Omitting the original article from the list of references implies an author's intention to withhold information and conceal misbehavior. In any case, self-plagiarized material should not be published.

The proposed new COPE guidelines define two distinct situations: when to propose revision and when to reject a submitted manuscript (1).

Based on the editorial policy of Biochemia Medica, upon detection of self-plagiarism, a submitted manuscript can be considered for publication only if it contains relevant new data and will contribute to overall scientific knowledge. Additional conditions have to be met:

1. When text similarity is observed with an author's previous publication, and the original publication is cited, the submitted manuscript has to be revised, with the questionable parts corrected. Overlaps within the methods section can be tolerated, but the cut-off percentage is for the editor to decide. Similarities in the introduction section can be approached differently from the treatment of overlaps in the discussion and conclusion sections.

2. When text similarity with an author's previous publication is seen, and the original publication is not cited, editors will oblige the author to correct the plagiarized text in the submitted manuscript and to cite the original article, as well as to point out new information in the submitted article.

Editors should reject the submitted manuscript when:
1. There are significant portions of self-plagiarized text. The value of "significant" is determined by each editor and re-evaluated on a case-to-case basis.

2. Plagiarized text contains already published data (not only methods section), and additional or relevant new data are absent. Publishing such manuscripts offers no scientific contribution.

3. Self-plagiarized text covers major sections of the discussion and conclusion.

4. There is obvious violation of copyright transfer. Similar actions are proposed when self-plagiarism is detected after publication. Editors should analyze the published paper and decide whether a corrected article or retraction needs to be published. An additional consideration has to be made on the article's publication date, as approaches toward self-plagiarism have been developing through the years. In general, corrective actions need not be taken if the article in question does not present duplicated data and has been published before 2004 (1). More detailed information on how to deal with cases of already published self-plagiarized articles are available from "COPE flowcharts for dealing with duplicate publications in a published article" and "COPE retraction guidelines" $(5,6)$.

Editors in Biochemia Medica embrace the highest standards of research integrity and good editorial practice and will process all submitted manuscripts in order to detect all forms of plagiarism and selfplagiarism. Introducing research integrity editor and the strict policy of checking all submitted manuscripts were recently established (7). The high quality of the journal is our obligation toward our readers. Thus, we call upon all authors and future authors to ensure responsible writing and check with their conscience as well as their manuscripts prior to submission.

\section{Potential conflict of interest}

None declared. 


\section{References}

1. Committee on publication ethics: Text recycling guidelines. Available at: http://publicationethics.org/text-recyclingguidelines. Accessed April 1, 2013.

2. Roig M. Plagiarism and self-plagiarism: What every author should know. Biochem Med 2010;20:295-300. http://dx.doi. org/10.11613/BM.2010.037.

3. Scanlon PM. Song from myself: an anatomy of self-plagiarism. Plagiary: Cross-Disciplinary Studies in Plagiarism, Fabrication, and Falsification 2007;2:57-66.

4. Committee on Publication Ethics. Flowchart: What to do if you suspect redundant (duplicate) publication (Suspected redundant publication in a submitted manuscript). Available at: http://publicationethics.org/files/u2/01A_Redundant_Submitted.pdf. Accessed April 1, 2013.
5. Committee on Publication Ethics. Flowchart: What to do if you suspect redundant (duplicate) publication (Suspected redundant publication in a published article). Available at: http://publicationethics.org/files/u2/01B_Redundant_Published.pdf. Accessed April 1, 2013.

6. Committee on Publication Ethics. Retraction guidelines. Available at: http://publicationethics.org/files/retraction\%20guidelines.pdf. Accessed April 1, 2013.

7. Simundic AM. Biochemia Medica appoints Research integrity editor. Biochem Med 2012;22:271. http://dx.doi. org/10.11613/BM.2012.028. 